\title{
Relationship between force platform and two functional tests for measuring balance in the elderly
}

\author{
Relação entre plataforma de força e dois testes funcionais \\ para medidas de equilíbrio em idosos
}

André W. O. Gil' ${ }^{1,2}$, Marcio R. Oliveira',2, Vinícius A. Coelho ${ }^{2,3}$, Carlos E. Carvalho ${ }^{1,2}$, Denilson C. Teixeira2, Rubens A. da Silva Jr,2,3,4

\begin{abstract}
Background: Clinical and laboratory methods have been developed to assess the different dimensions of postural control with the aim to increase the clinical relevance of decisions about balance deficit. Objectives: The purpose of this study was to correlate the force platform measurements with two functional tests used to evaluate balance in elderly. Methods: A total of 124 physically independent elderly volunteers participated in this study. Subjects performed the following three tests: 1) a traditional functional balance test, named the one-leg standing test, which measures the time in seconds at this position; 2) a functionalagility/dynamic balance test, which quantifies the total time in seconds that a subject canstand up from a chair and move as quickly as possible around two cones; and 3) an unipodal balance test on a force platform. Results: The one-leg standing test yielded a mean of 12 seconds ( $S D=9 \mathrm{~s}$ ), while the mean time observed in the functional agility/dynamic balance test was 26 seconds ( $S D=6 \mathrm{~s}$ ). The correlations between the balance parameters of force platform and two functional tests varied between -0.28 and 0.20 , which shows a weak association between them. Conclusions: Our results support the idea that these functional tests do not necessarily furnish the same information regarding balance mechanisms as the force platform. This study contributes to the evaluation of balance in elderly and suggests that functional tests should be used with caution especially in regards to the purposes of the research and when conducting clinical assessments of the elderly.
\end{abstract}

Keywords: posture; aging; movement; biomechanics; rehabilitation

\section{Resumo}

Contextualização: Diferentes métodos clínicos e laboratoriais têm sido desenvolvidos para avaliar as dimensões do controle postural a fim de aumentar a relevância clínica nas decisões quanto ao déficit de equilíbrio. Objetivos: Correlacionar as medidas de plataforma de força com dois testes funcionais usados para avaliar o equilíbrio em idosos. Métodos: Cento e vinte e quatro idosos fisicamente independentes e voluntários participaram deste estudo. Os sujeitos realizaram três testes: 1) teste tradicional e funcional de equilíbrio estático, que mede o tempo-limite em segundos de apoio unipodal; 2) teste funcional de agilidade e equilíbrio dinâmico, que quantifica o tempo total em segundos para realizar uma tarefa de sentar, levantar e locomover-se o mais rápido possível em torno de dois cones e 3) teste de equilíbrio unipodal sobre uma plataforma de força. Resultados: A média do tempo-limite para o teste funcional de equilíbrio estático foi de 12 segundos (DP=9s), enquanto a média de tempo para o teste funcional de agilidade e equilíbrio dinâmico foi de 26 segundos ( $\mathrm{DP}=6 \mathrm{~s})$. As correlações entre os parâmetros de equilíbrio da plataforma de força e os testes funcionais variaram entre $-0,28$ e 0,20, sugerindo uma associação fraca entre eles. Conclusões: Os resultados suportam a ideia de que os dois testes funcionais não fornecem, necessariamente, a mesma informação que uma plataforma fornece quanto aos mecanismos de controle postural para equilíbrio. Este estudo colabora para a avaliação do equilíbrio em idosos e sugere que alguns testes funcionais deveriam ser usados com mais cautela quanto à sua indicação no alcance dos objetivos da pesquisa e na identificação dos possíveis déficits de equilíbrio, especialmente quando usados para avaliação clínica de idosos.

Palavras-chave: postura; envelhecimento; movimento; biomecânica; reabilitação.

\section{Received: 01/03/2011 - Revised: 05/03/2011 - Accepted: 08/10/2011}

\footnotetext{
'Physical Therapy Department, Center for Biological Health Sciences (CCBS), Universidade Norte do Paraná (UNOPAR), Londrina, PR, Brazi

Center for Health Science Research, Laboratory of functional evaluation and human motor performance, UNOPAR

${ }^{3}$ Masters Program in Rehabilitation Sciences, UEL/UNOPAR, Londrina, PR, Brazil

${ }^{4}$ Physical Therapy Department, Universidade Estadual de Londrina (UEL), Londrina (PR), Brazil

Correspondence to: Rubens Alexandre da Silva Jr, Center for Health Science Research, Universidade Norte do Paraná (UNOPAR), Av. Paris, 675, Jardim Piza, Caixa Postal 401, CEP 86041-140, Londrina, PR, Brasil, e-mail: rubens@unopar.br
} 


\section{Introduction $: \because$.}

The increase in the number of individuals over 60 years old is a worldwide phenomenon. Currently in Brazil, the population over 60 is approximately 15.8 million, or $9 \%$ of the total population according to data from the Brazilian Institute of Geography and Statistics ${ }^{1}$. This aging of the population is due to a combination of three factors: a reduction in birth rate, a reduction in death rate and an increase in life expectancy ${ }^{2}$.

Physiological and morphological changes that occur in the musculoskeletal system during the aging process ${ }^{2-4}$ such as reductions in muscular performance and muscular strength, have certain effects on the functional capacity of the elderly ${ }^{3,5-8}$. Postural control can also deteriorate as part of the aging process and in conjunction with the other age related chances can lead to a decrease in balance and increase in the risk of falls ${ }^{4,9-12}$.

Different clinical and laboratory methods have been developed to assess the different dimensions of postural control in order to increase the clinical relevance of decisions regarding balance deficit and fall prevention. In the present study, postural control will be referred to as "balance", whichis a generic term used to describe the body's ability to adjust the centerof-pressure (COP) to maintain projection of its center of mass $(\mathrm{COM})$ within the manageable limits of the base of support ${ }^{13}$. Balance can also refer to the functional ability to stay upright or to recover equilibrium after external perturbations or challenging postures involved indifferent tasks ${ }^{14-19}$.

Single task performance is often used in the clinical setting for measuring balance. Measurements typically either assess aspects of postural maintenance such as those necessary for basic upright balance, or simple ambulation performance. More specifically, functional balance tests such as those employed with the Tinetti and Berg scales ${ }^{9,11,12}$, as well as agility/ dynamic balance test ${ }^{20}$, are used to estimate the risk of fall among elderly. However, as with any single domain measure, critical information about balance could be lost. Apparently, only the parameters of a force platform can reveal with precision the degree of balance deficit associated with biomechanical and neuromuscular control strategies for maintaining equilibrium ${ }^{13,21}$. Parameters of postural stability such as COP displacement, which is defined as the point of location of the vertical ground reaction force vector during force platform measurements ${ }^{13}$, is generally used to measure the strategies of balance among different populations ${ }^{5,22-24}$.

Some studies have correlated some functional measurements of physical performance or balance functional tests (e.g., Berg scales, time-up-and-go, functional reach, one-leg stance, mobility: SOMAI) with measurements based on force platform parameters in order to establish agreement. However, these studies were carried out in different populations (e.g., healthy elderly, menopausal women adults, pathologic elderly) $5,6,25,26$ and were assessed using force platform balance parameters in bipedal position only. The use of this position limits the clinical usefulness of data for documenting balance deficits in both healthy elderly and those undergoing rehabilitation programs, since standing still on both legs is not a major challenge to our balance control system. It would be also interesting to evaluate these correlations during functional situations such as one-leg stance task on force platform measurements. Moreover, the small sample size of other correlation studies ${ }^{25,26}$ is also a limiting factor for their conclusions.

Therefore, the main purpose of this study was to determine the relationship between the main COP balance parameters measured by a force platform during a task (one-leg stance) that is assumed to be challenging for the elderly with two common functional balance tests (traditional one-leg stance and agility/dynamic balance tests) used for balance assessments.

\section{Methods $\because:$}

\section{Participants}

A total of 124 (men=40) elderly volunteers participated in the present study. The characteristics of the elderly are presented in the Table 1. All participants in this study were a subsample from a larger project entitled "Epidemiological Study of the Sociodemographic Factors and Indicators of Elderly Health Conditions in the City of Londrina (EELO)" conducted at the Universidade Norte do Paraná (UNOPAR), Londrina, PR, Brazil, between 2009 and 2010.

All elderly were recruited by convenience from the local community. Criteria for inclusion in this study were as follow: aged over 60 years, living independently and classified with a functional state level of 3, 4 or 5 with regard to the activities of daily living (in mean state as 3 in the present study) ${ }^{27}$ and cognitive status score $>18$ on the Mini-Mental State Examination $^{5}$. General exclusion criteria were as follow: self-reported

Table 1. Characteristics of participants.

\begin{tabular}{lccc} 
& $\begin{array}{c}\text { Women }(\mathrm{n}=84) \\
\text { Mean }(\mathrm{SD})\end{array}$ & $\begin{array}{c}\text { Men }(\mathrm{n}=40) \\
\text { Mean }(\mathrm{SD})\end{array}$ & $\begin{array}{c}\text { All elderly }(\mathrm{n}=124) \\
\text { Mean (SD) }\end{array}$ \\
\hline Age $(\mathrm{yrs})$ & $69(5)$ & $68(5)$ & $69(6)$ \\
\hline Weight $(\mathrm{kg})$ & $66.11(12)$ & $73.31(17)$ & $68.45(14)$ \\
\hline Height $(\mathrm{m})$ & $1.56(0.8)$ & $1.63(13.4)$ & $1.58(0.09)$ \\
\hline BMl $\left(\mathrm{kg} / \mathrm{m}^{2}\right)$ & $27(4.6)$ & $27(5)$ & $27(4)$ \\
\hline Cognitive status $^{\star}$ & $23(3.8)$ & $24(4)$ & $23(4)$ \\
\hline Physical activity level $^{\ddagger}$ & $5.70(3.6)^{\ddagger}$ & $7.52(6)$ & $6.30(4)$ \\
\hline
\end{tabular}

Mean values with standard deviation (SD); BMI=Body Mass Index; * Mini-Mental State Examination (normal range based in a cut off $>18$ ) ${ }^{5}$; ${ }^{*}$ Baecke modified questionnaire for older people $e^{28,29}$. 
injuries, illnesses, falls in the past year, musculoskeletal disorders, systemic-neurological-degenerative disease, severe labyrinthitis and chronic diseases of the cardiovascular or the respiratory system. To determine the level of physical activity, a short versions Baecke modified questionnaire adapted for the elderly was used for all volunteers ${ }^{28,29}$. The participants were informed about the experimental protocol and the potential risks of the study and gave written consent before their participation. The protocol and the consent form had been previously approved by the local Ethics committee UNOPAR (CEP/ protocol PP070/09).

\section{Assessments}

Two sessions of approximately 2 hours and separated by a maximum of 72 hours were necessary. The same investigators performed the procedures with all participants at the same laboratory to ensure uniformity. The physical tests were employed on two different days: (1) session one: functional tests (traditional one-leg stance and agility/dynamic balance tests); (2) session two: balance test using force platform measurement.The order of the tests on the two separate days was not random as data collection followed the experimental design of the Epidemiological Study of the Sociodemographic Factors and Indicators of Elderly Health Conditions in the City of Londrina (EELO), carried out at the UNOPAR.

\section{Experimental Protocol}

On the first functional test volunteers remained in a unipodal stance on the lower limb of choice with arms akimbo and eyes opened and focused on a fixed point at a distance of approximately $2 \mathrm{~m}^{30}$. The volunteers were then asked to flex the tested lower limb at the knee and encouraged to maintain this position for at least 30 seconds as recommended on the traditional protocol of test (Figure 1A). A trained examiner remained beside the volunteer throughout the test both for security and to record the performance time. A chronometer was used to measure the time that a volunteer was able to remain on the test position, which was denominated time-limit (Tlimit). The Tlimit was defined as the maximum time before a volunteer suddenly abandoned the posture due to loss of balance, i.e., when the lifted foot touched either the force platform or the floor ${ }^{30}$. Three attempts were performed separated by brief recovery periods (30 s average). The mean in seconds was recorded for analysis ${ }^{30}$.

Five minutes after the first test, the second functional test (agility/dynamic balance test) was conducted ${ }^{20}$. This test is recommended by the American Alliance for Health, Physical Education, Recreation \& Dance (AAHPERD) ${ }^{20}$. This test evaluated the time that the individual took to perform a task. Volunteers were initially seated in a standardized chair with heels planted on the floor and upon hearing a signal, got up and moved first to the right, circling a cone positioned $1.50 \mathrm{~m}$ behind and $1.80 \mathrm{~m}$ to the side of the chair (Figure 1B), returned to sit in the chair, briefly elevated the feet, and then repeated the circling action with another cone placed symmetrically on the left side, returning finally to the original position in the chair. Two tests were conducted in this circuit and the best performance (Tshortest) in seconds was recorded as the final result.

At session two, all volunteer performed three trials of the one-leg stance test maintained for a maximum of 30 seconds on a force platform, with a rest period of approximately $30 \mathrm{sec}$ onds between each trial ${ }^{31}$. The mean across three trials for each balance parameters (detailed below) was retained for analysis in order to improving the reliability of the data ${ }^{32}$. During all trials on the force platform each participant was instructed to

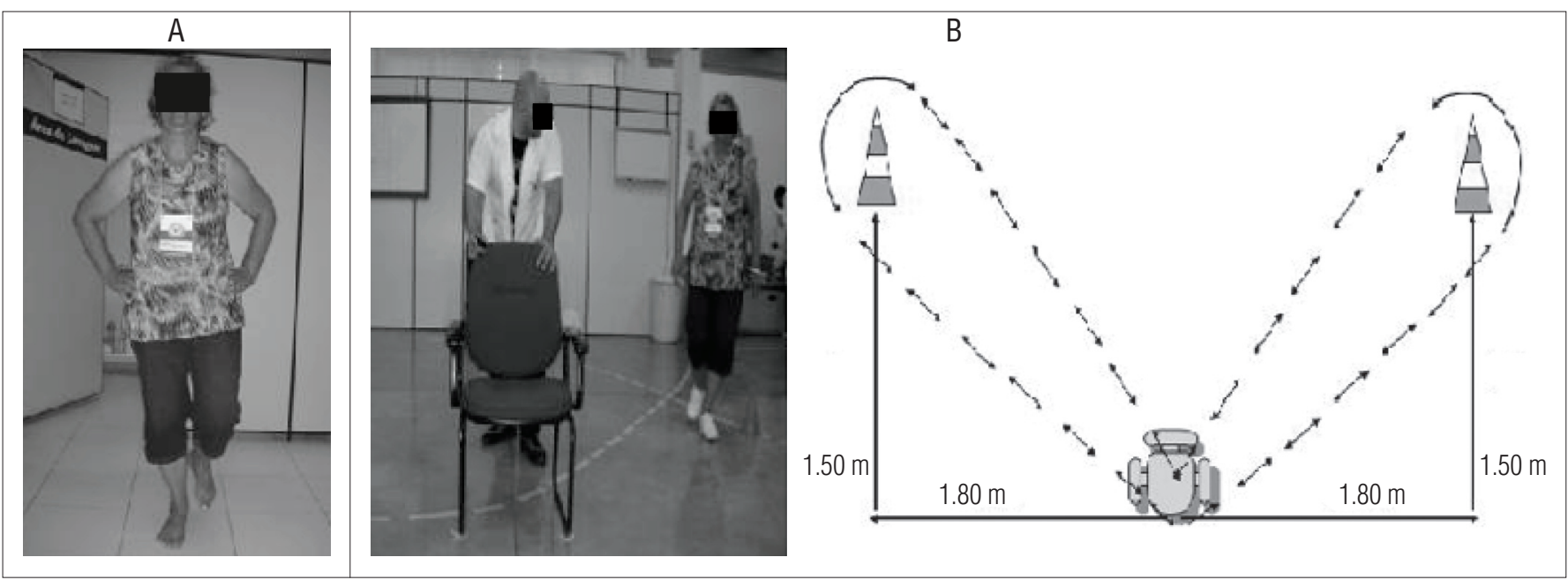

Figure 1. The one-leg stance functional balance test (A) and the agility/dynamic balance test (B). 
stand on the preferred leg barefoot, eyes opened and looking at a target (cross) placed on a wall at eye level 2 meters away, arms along the side of the body or parallel to trunk (see Figure 2 for illustration). To prevent falls or injuries an examiner stood close to the volunteers during all tasks.

\section{Computation of COP-based balance parameters}

The COP-based balance parameters were computed with the use of a BIOMEC400 force platform. The force platform contains four strain gauges arrayed in a rectangle. The sensitivity of each sensor is certified to be $0.0015 \%$ for a maximum load of $1000 \mathrm{~N}$. A variation of $9.999 \mathrm{~N}$ of the force applied to one strain gauge corresponds to a $120-\mathrm{mV}$ variation of the output. The output range runs from 0 to $5 \mathrm{~V}$. The system uses a 16-bit analog-to-digital converter and a $50-\mathrm{Hz}$ notch filter before the analog-digital conversion. During data collection, the vertical ground reaction force signals were sampled at $100 \mathrm{~Hz}$. The digital data were transferred via USB cable to a PC with customized software.

All force signals from the platform were filtered with a 35-Hz low-pass second-order Butterworth filter and converted into COP data using EMG System do Brasil software, which

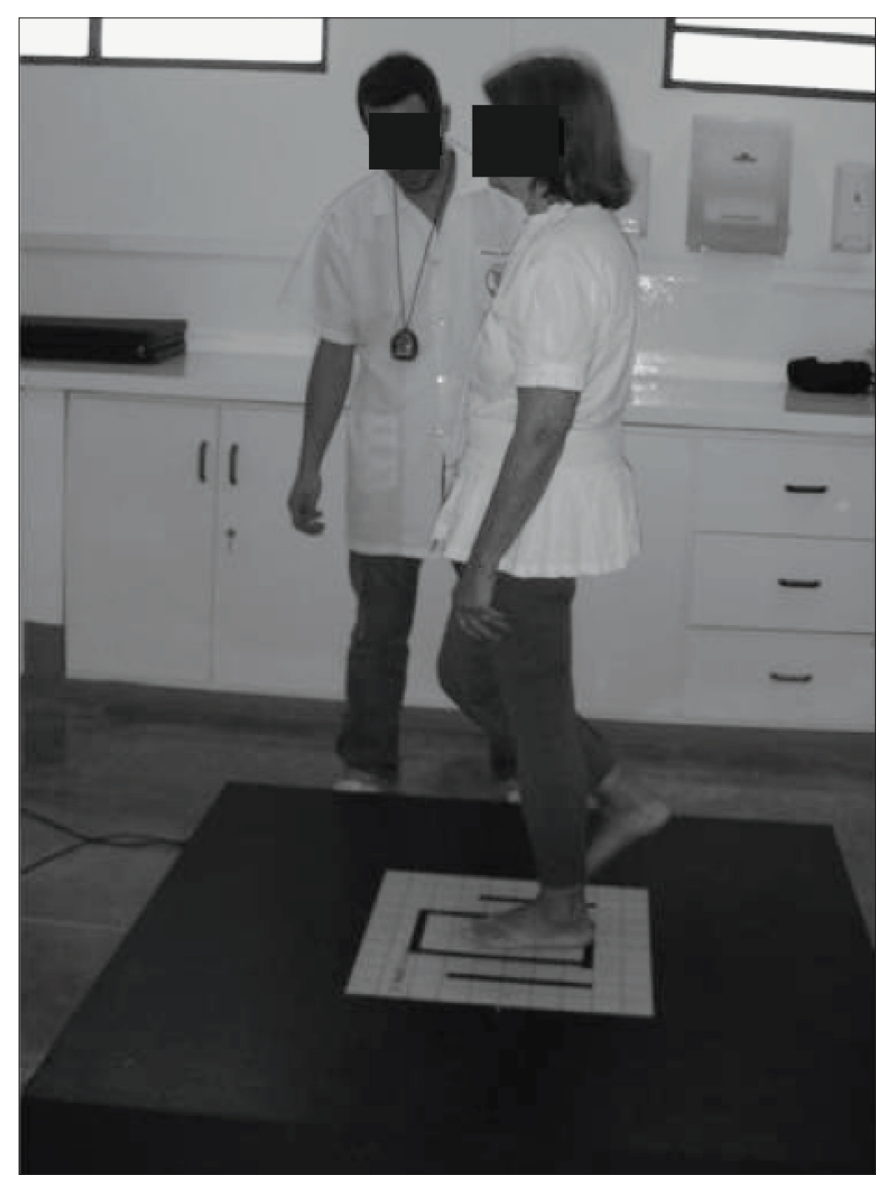

Figure 2. Subject's position on the force platform (model BIOMEC400) during one-leg standing for balance test. was compiled with MATLAB routines (The Mathworks, Natick, MA). Stabilographic analysis of COP data led to the calculation of the following balance parameters: $95 \%$ confidence ellipse area of COP (A-COP in $\mathrm{cm}^{2}$ ), Root Mean Square (RMS) amplitude of COP sway (RMS in $\mathrm{cm}$ ), and mean velocity (MVeloc in $\mathrm{cm} / \mathrm{s}$ ) and mean frequency (MF in $\mathrm{Hz}$ ) of COP for both anteroposterior $(\mathrm{A} / \mathrm{P})$ and mediolateral $(\mathrm{M} / \mathrm{L})$ directions. These balance parameters were calculated for either the entire test period, when this upper limit was reached, or for the time-limit that the participant reached. Participant force platform timeseries values ranged from 2.5 to 30 seconds, with a mean value of 12.3 ( $\mathrm{SD}=3$ ). The reliability and validity of BIOMEC400 force plate measurements have been previously established in both elderly and young adults ${ }^{33}$.

\section{Statistical analysis}

All statistical analyses were performed with NCSS statistical software (version 6.0 for Windows) with an alpha level of 0.05. All variables were normally distributed, as verified with the Shapiro-Wilk test and the Kurtosis normality test. Pearson's correlation coefficients were used to assess the level and direction of the relationship between all balance parameters (A-COP, RMS, MVeloc, MF in two directions A/P and $\mathrm{M} / \mathrm{L}$ ) obtained with the force platform and the two functional tests (Tlimit and Tshortest). We also used Student's t-test to compare the time-limit (Tlimit) from functional test with time values from force platform time-series data.

\section{Results $: \because$}

The mean Tlimit during the functional test was 12.8 seconds $(\mathrm{SD}=9 \mathrm{~s})$, while the mean Tshortest was 26 seconds $(\mathrm{SD}=6 \mathrm{~s})$, see Table 2. As expected, no significant differences $(\mathrm{p}=0.458$, Student's $t$ - test) were found between time (12.3 s) recorded by the force platform and the Tlimit (12.8 s) from the functional test (Table 2), which demonstrates the consistency of data for this domain even when collected on different days.

Table 2. Time values from force platform time-series data and functional tests.

\begin{tabular}{lcc}
\hline Variables $^{\mathrm{a}}$ & Mean (SD) & \\
\hline Tshortest & $26(6)$ & \\
\hline Tlimit & $12.8(9)$ & Student's t-test* $^{\star} \mathrm{p}$ value) \\
\hline Time of force platform & $12.3(3)$ & 0.458 \\
\hline
\end{tabular}

Mean values with standard deviation (SD). ${ }^{\mathrm{a} T}$ Thortest: performance score of functiona agility/dynamic balance test. Tlimit: performance score from traditional one-leg stance test. Time of force platform: time values from time-series data of force platform, ranging from 0.5 to 30 seconds. ${ }^{*}$ Student's t-test between e Tlimit and time values from force platform. No significant difference was found between the two tasks. 
Table 3. Pearson's correlations between all plataform balance parameters and the two functional balance tests.

\begin{tabular}{lccc} 
Variables & $\begin{array}{c}\text { Force platform } \\
\text { Mean (SD) }\end{array}$ & $\begin{array}{c}\text { Tlimit (12.8 s) } \\
r \text { Pearson's } \\
(p \text { values) }\end{array}$ & $\begin{array}{c}\text { Tshortest }(26 \mathrm{~s}) \\
r \text { Pearson's } \\
(p \text { values) }\end{array}$ \\
\hline A-COP $\left(\mathrm{cm}^{2}\right)$ & $22.6(24)$ & $-0.28(0.002)^{\star}$ & $0.12(0.177)$ \\
\hline RMS A/P (cm) & $4.7(2.0)$ & $-0.11(0.248)$ & $0.02(0.770)$ \\
\hline RMS M/L (cm) & $5.9(2.9)$ & $-0.24(0.009)^{\star}$ & $0.20(0.037)^{\star}$ \\
\hline MVeloc A/P (cm.s) & $4.5(2.5)$ & $-0.20(0.025)^{\star}$ & $0.01(0.845)$ \\
\hline MVeloc M/L (cm.s) & $4.8(1.7)$ & $-0.22(0.011)^{\star}$ & $0.09(0.304)$ \\
\hline MF A/P (Hz) & $1.05(0.52)$ & $-0.23(0.009)^{\star}$ & $0.05(0.582)$ \\
\hline MF M/L (Hz) & $1.12(0.44)$ & $-0.18(0.041)^{\star}$ & $0.01(0.871)$ \\
\hline
\end{tabular}

Mean values with standard deviation (SD). Pearson's Coefficients $(r)$. * Significant correlations ( $P<0.05)$. aBalance parameters from force platform (see methods for more details). Tlimit: time score computed during one-leg stance functional test. Tshortest: time score computed during functional agility/dynamic balance test.

The correlations between the balance parameters obtained with the force platform and the functional tests varied between $-0.28(\mathrm{p}=0.002)$ and $0.20(\mathrm{p}=0.037)$, which indicated a weak association between them (Table 3). The most significant (although low) correlations were for Tlimit with the platform parameters A-COP, MVeloc and MF, while no significant correlation was found with Tshortest except the RMS parameter (see Table 3).

\section{Discussion $: \because$.}

The objective of the present study was to determine the relationship between a number of balance parameters registered by a force platform during a one-leg stance task and common functional balance tests used for balance assessment in elderly.

The evaluation of postural stability is generally recommended before rehabilitation and exercise programs for the treatment of specific balance deficits. The functional tests of physical performance designed for this context are simple, take a minimal amount of time to complete and are easy to use. These tests are also relevant for determining the physical performance of the individual although they incorporate too many abilities (e.g., strength, endurance, flexibility and coordination $)^{4,9-12}$. The measurement tool used for these tests is the time recorded on a chronometer for performing a functional task such as getting up from a chair, circling a cone and returning, remaining in a unipodal stance, or walking a distance of $10 \mathrm{~m}$ as fast as possible $\mathrm{e}^{7,11,24,34}$. However, this variable, although predictive, includes only a single domain of postural control and thus presents certain disadvantages in identifying the type of balance problems an individual may have? Although the previously described tests used in the present study have been proven valid for predicting the likelihood of future falls, these tests do not help clinicians to focus the development of a treatment program on the real underlying causes of balance deficit ${ }^{7,11}$.

The results of this study suggest that COP sway parameters from the force platform more likely capture sensorimotor deficits than differentiate functional performance abilities. A weak $(\leq-0.28)$ correlation was found between the COP and the Tlimit of the functional test (see Table 3). Moreover, there was a lack of correlation between $\mathrm{COP}$ and the agility/dynamic balance test. These results agree with other studies, even those using different balance protocols ${ }^{5,6,25,26}$, that have also observed weak, moderate or even no association between the COP parameters and functional tests. In a study that evaluated a sample of elderly $(n=100)$ similar to that of the present study, except with a bipodal balance protocol, the same results were observed, i.e., a weak $(r=-0.25)$ or no correlation between the parameters of COP oscillation and the different functional performance tests employed in the study (ex: functional reach, timed 10-meter walk, mobility) $)^{5}$. A more recent study ${ }^{25}$ that evaluated the validity of a functional stability test as a measure of balance compared to COP measurements in adults aged 23 to 73 years, also showed a weak ( $r=-0.19$ to 0.08 ) correlation between functional performance and COP sway parameters. All these results as well as those of the present study indicate that functional tests based on physical performance do not necessarily furnish the same information on balance mechanisms as the force platform. This has many implications for both the prevention and rehabilitation perspectives based on balance assessment in elderly.

However, it is worth noting that both protocols of balance evaluation (force platform, functional tests) are often multifaceted $^{21,35}$ and the nature of each task could also explain the negative results of the present study. Nevertheless, a dysfunction in the ability of an individual to maintain or restore a state of equilibrium implies a deficit in postural control. Any cognitive, proprioception (sensory and motor), muscular strength, or motor coordination impairment could result in postural control deficits and clinical balance assessment tools can provide some information on a variety of dimensions of postural control deficits ${ }^{7,21,35}$. Functional tests can measure balance deficit indirectly through the recorded time of physical performance (i.e. one aspect of physical condition or capacity), while COP parameters from a force platform can directly analyze balance deficits (postural adjustments and responses, postural stability limits, ability to recovery the balance) $)^{5,13,21-24}$.

The values found in the present study for both functional test performance time and force platform balance parameters agree with other studies ${ }^{5,17,25,36-38}$ despite their different protocols and purposes. In general, physical (Tlimit, Tshorstest) and balance (COP parameters) performance in elderly can be associated with the aging process from muscular weakness, lack of mobility, sensory-motor deficits ${ }^{3,8}$. Furthermore, the physical 
activity level of our sample of volunteers was classified as low according to the results of the Baecke questionnaire (average index $=6$, see Table 1 ). Thus, it is possible that the physical inactivity of our sample negatively affected balance control, which could impact functional performance.

Finally, the overall results of this study cannot necessarily be generalized to all elderly because our sample of subjects was not large enough to represent the heterogeneity of elderly with different aging processes. Another limitation of the present study is that we did not evaluate any other functional tests besides the traditional one-leg stance and balance/dynamic agility, which may have limited the scope of our results. Our results may not be generalized to other force platform protocols that use different time sampling $(60,120 \mathrm{~s})$, tasks (tandem, eyes closed, quiet standing) or balance sway measures than those used in the present study. Another limitation was that arms position from functional test and platform protocol were different. Also, there was no comparison between genders because we used a convenience sample that was not paired by gender (only 40 men). Regarding the project design, our results should be taken with caution since the evaluations were conducted on different days and the tasks were not assigned randomly. However, no significant differences were found between times recorded by the force platform and the traditional functional one-leg stance test, which supported the consistency of our measures even when collected on different days.

In conclusion, since balance is an important clinical outcome, as suggested by prospective studies ${ }^{10}$, therapists in clinical or rehabilitation centers should attempt to design a more specific evaluation tool for identifying whether balance problem exists. Our results support the notion that functional tests do not necessarily furnish the same information regarding balance mechanisms as force platforms. This study contributes to the evaluation of balance in elderly and suggests that some functional tests should be used with caution depending on the purposes of the research and also when identifying balance deficits, especially in clinical assessments of the elderly.

\section{Acknowledgements $: \because$.}

Fundação Nacional de Desenvolvimento do Ensino Superior Particular (FUNADESP) for research grant; Programa Institucional de Bolsas de Iniciação Científica/Conselho Nacional de Desenvolvimento Científico e Tecnológico (PIBIC/CNPQ) for student scholarship. All elderly volunteers for their willingness and participation in the project.

\section{References $: \therefore$.}

1. IBGE. IBGE (Fundação Instituto Brasileiro de Geografia e Estatística). Censo Demográfico: Brasil; 2000

2. Ferrucci L, Giallauria F, Guralnik JM. Epidemiology of aging. Radiol Clin North Am. 2008;46(4):643-52

3. Piirtola M, Era P. Force platform measurements as predictors of falls among older people - a review. Gerontolology. 2006;52(1):1-16

4. Rubenstein LZ. Falls in older people: epidemiology, risk factors and strategies for prevention. Age Ageing. 2006;35 Suppl 2:ii37-41.

5. Hughes MA, Duncan PW, Rose DK, Chandler JM, Studenski SA. The relationship of postural sway to sensorimotor function, functional performance, and disability in the elderly. Arch Phys Med Rehabil. 1996;77(6):567-72

6. Lindmark B, Lagerström C, Naessén T, Larsen HC, Persson I. Performance in functional balance tests during menopausal hormone replacement: a double-blind placebo-controlled study. Physiother Res Int. 1999;4(1):43-54.

7. Mancini M, Horak FB. The relevance of clinical balance assessment tools to differentiate balance deficits. Eur J Phys Rehabil Med. 2010;46(2):239-48.

8. Orr R. Contribution of muscle weakness to postural instability in the elderly. A systematic review. Eur J Phys Rehabil Med. 2010;46(2):183-220.

9. Berg KO, Maki BE, Williams JI, Holliday PJ, Wood-Dauphinee SL. Clinical and laboratory measures of postural balance in an elderly population. Arch Phys Med Rehabil. 1992;73(11):1073-80.

10. Lord SR, Sherrington C, Menz HB. Falls in older people: risk factors and strategies for prevention. New York : Cambridge University press; 2001.

11. Persad CC, Cook S, Giordani B. Assessing falls in the elderly: should we use simple screening tests or a comprehensive fall risk evaluation? Eur J Phys Rehabil Med. 2010;46(2):249-59.

12. Tinetti ME, Speechley M, Ginter SF. Risk factors for falls among elderly persons living in the community. N Engl J Med. 1988;319(26):1701-7.
13. Winter DA. Human balance and posture control during standing and walking. Gait Posture. 1995;3(4):193-214

14. Bauer $C$, Gröger I, Rupprecht $R$, Gassmann $K G$. Intrasession reliability of force platform parameters in community-dwelling older adults. Arch Phys Med Rehabil. 2008;89(10):1977-82.

15. Goldie PA, Bach TM, Evans OM. Force plataform measures for evaluating postural control: reliability and validity. Arch Phys Med Rehabil. 1989;70(7):510-7.

16. Lafond $D$, Corriveau $H$, Hébert $R$, Prince $F$. Intrasession reliability of center of pressure measures of postural steadiness in healthy elderly people. Arch Phys Med Rehabil. 2004;85(6):896-901.

17. Lin D, Seol H, Nussbaum MA, Madigan ML. Reliability of COP-based postural sway measures and age-related differences. Gait Posture. 2008;28(2):337-42.

18. Pinsault N, Vuillerme N. Test-retest reliability of centre of foot pressure measures to assess postural control during unperturbed stance. Med Eng Phys. 2009;31(2):276-86.

19. Santos BR, Delisle A, Larivière C, Plamondon A, Imbeau D. Reliability of centre of pressure summary measures of postural steadiness in healthy young adults. Gait Posture. 2008;27(3):408-15.

20. Osness W, Adrian M, Clark B, Hoeger W, Raab D, Wiswell R. Functional fitness assessment for adults over 60 years. American Alliance for Health, Physical Education, Recreation and Dance. Reston; 1990

21. Howe TE, Rochester L, Jackson A, Banks PM, Blair VA. Exercise for improving balance in older people (Review). Cochrane Database Syst Rev. 2009;1-150.

22. Lacour M, Barthelemy J, Borel L, Magnan J, Xerri C, Chays A, et al. Sensory strategies in human postural control before and after unilateral vestibular neurotomy. Exp Brain Res. 1997;115(2):300-10.

23. Melzer I, Benjuya N, Kaplanski J. Postural stability in the elderly: a comparison between fallers and non-fallers. Age Ageing. 2004;33(6):602-7.

24. Nardone A, Schieppati M. The role of instrumental assessment of balance in clinical decision making. Eur J Phys Rehabil Med. 2010;46(2):221-37. 
25. Holbein-Jenny MA, MCDermott K, Shaw C, Demchak J. Validity of functional stability limits as a measure of balance in adults aged 23-73 years. Ergonomics. 2007;50(5):631-46.

26. Tang PF, Moore S, Woollacott MH. Correlation between two clinical balance measures in older adults: functional mobility and sensory organization test. J Gerontol A Biol Sci Med Sci. 1998;53(2):M140-6

27. Spirduso WW. Physical dimensions of aging. Champaign, IL: Human Kinetics; 1995

28. Mazo GZ, Mota J, Benedetti TB, Barros MVG. Validade Concorrente e reprodutibilidade teste-reteste do questionário de Baecke modificado para idosos. Rev Bras Ativ Fís Saúde. 2001;6(1):5-11.

29. Voorrips LE, Ravelli AC, Dongelmans PC, Deurenberg P, van Staveren WA. A physical activity questionnaire for the elderly. Med Sci Sports Exerc. 1991;23(8):974-9.

30. Greene LS, Willians HG, Macera CA, Carter JS. Identifying dimensions of physical (motor) functional capacity in healthy older adults. J Aging Health. 1993;5(2):163-78.

31. Gribble PA, Hertel J. Effect of hip and ankle muscle fatigue on unipedal postural control. J Electromyogr Kinesiol. 2004;14(6):641-6.

32. Corriveau H, Hébert R, Prince F, Raiche M. Intrasession reliability of the "center of pressure minus center of mass" variable of postural control in the healthy elderly. Arch Phys Med Rehabil. 2000;81(1):45-8

33. Da Silva RA, Parreira RB, Medonça L, Ghizoni J, Vitor LG, Teixeira DC, et al. Developing validity and reliability of a new force plataform-based in balance measures in older and young adults. Society for Neuroscience. Proceeding in the 40 Neuroscience Meeting, San Diego, 2010 1206-7.

34. Michikawa T, Nishiwaki Y, Takebayashi T, Toyama Y. One-leg standing test for elderly populations. J Orthop Sci. 2009;14(5):675-85.

35. Pollock AS, Durward BR, Rowe PJ, Paul JP. What is balance? Clin Rehabil. 2000;14(4):402-6

36. Fregly AR, Smith MJ, Graybiel A. Revised normative standards of performance of men on a quantitative ataxia test battery. Acta Otolaryngol. 1973;75(1):10-6

37. Hernandez SSS, Coelho FGM, Gobbi S, Stella F. Effects of physical activity on cognitive functions, balance and risk of falls in elderly patients with Alzheimer's dementia. Rev Bras Fisioter. 2010;14(1):68-74

38. Jonsson E, Seiger A, Hirschfeld $\mathrm{H}$. One-leg stance in healthy young and elderly adults: a measure of postural steadiness? Clin Biomech (Bristol, Avon). 2004;19(7):688-94. 